\title{
Evaluating seismic reliability of Reinforced Concrete Bridge in view of their rehabilitation
}

\author{
Hasnae BOUBEL*, Oumnia ELMRABET, Mohamed ROUGUI , Ouadia MOUHAT, Echebba EL Mehdi. \\ Structure LGCE l'EST, Salé -CED de l'EMI, Mohammed V University in Rabat-MOROCCO
}

\begin{abstract}
Considering in this work, a simplified methodology was proposed in order to evaluate seismic vulnerability of Reinforced Concrete Bridge. Reliability assessment of stress limits state and the applied loading which are assumed to be random variables. It is assumed that only their means and standard deviations are known while no information is available about their densities of probabilities. First Order Reliability Method is applied to a response surface representation of the stress limit state obtained through quadratic polynomial regression of finite element results. Then a parametric study is performed regarding the influence of the distributions of probabilities chosen to model the problem uncertainties for Reinforced Concrete Bridge. It is shown that the probability of failure depends largely on the chosen densities of probabilities, mainly in the useful domain of small failure probabilities.
\end{abstract}

KEYWORDS: Reliability, ANOVA, Nonlinear, Analysis of variance, finite element method, ANSYS

\section{Introduction}

Many structures, including bridges, built before 1970 are not adequately detailed for seismic actions. This means bridge structures have historically been vulnerable to seismic loading, with a large number of examples of damage occurring to both superstructure and substructure elements and, in some cases, complete and catastrophic collapse. The turning point event in changing structural design philosophy was the 1971 San Fernando earthquake [1]. That event caused severe damage to major lifelines, including the transportation lifeline. Bridges, an important component of the transportation lifeline, suffered major damage. This prompted almost all the state departments of transportation in earthquake prone areas to upgrade their design specifications and structural details to resist earthquake action, as did the Federal Highway Administration. However, even with this, there are still many existing older bridges that were designed and built prior to 1971. It is critical that these bridges be upgraded to current seismic design standards in regions with strong earthquake potential. While many methods and approaches are available to accomplish this, methods to systematically and rationally compare these methods and select the optimal method are lacking, particularly in terms of target performance levels [2-3]. The aim of this research is to explore one such method based on fragility analyses.

\section{Materials and methods}

\subsection{Modeling the Structure}

The bridge studied is located in province Al Hoceima, This structure consists of five simple spans of $35 \mathrm{~m}$ each. In turn, each bay consists of three equidistant beams transversely. The platform of the structure has a width of $10 \mathrm{~m}$ with a floor of $7.80 \mathrm{~m}$ and two sidewalks of $1.50 \mathrm{~m}$ and $0.70 \mathrm{~m}$. The section of $2.30 \mathrm{~m}$ total height deck is formed by three beams spaced $3.40 \mathrm{~m}$.

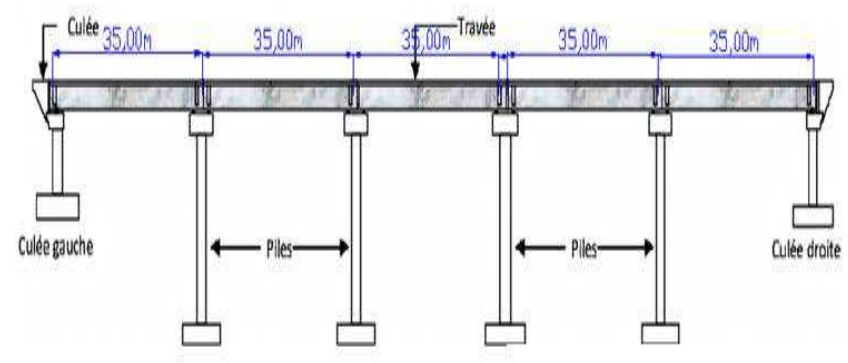

Fig. 1. Long profile 


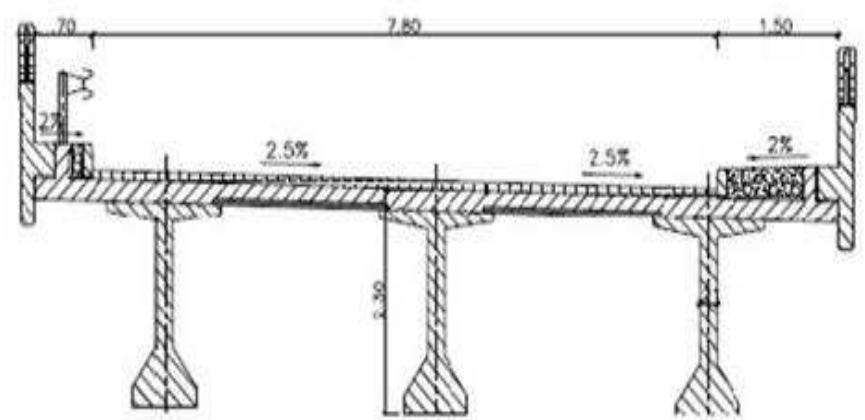

Fig. 2. Cross section of apron

\subsection{Loading Idealization}

The purpose of this study is to analyze the effect of horizontal and vertical earthquake ground motion on bridges. The focus is on the variations of earthquake loading rather than the gravity load. Loading considers the gravity load (self-weight, superimposed load and traffic load) and earthquake loading.

The dead load of the deck is distributed to the beams based on their respective tributary widths. Superimposed dead loads (wearing course, future wearing surface, railings, barriers), with the exception of footpath loads, are to be distributed equally to all beam lines. Superimposed load is achieved by multiplying the density of material by the area of the elements. The calculation of the superimposed load is as follow:

\section{System A (L):}

\section{$A L=\max (0,23+36 / L+12 ; 0,4-0,2 L / 1000)$ en $t / m^{2}$}

Case of a single loaded channel, we have: a1 $=1$, a $2=$ $0.96, \mathrm{~V}=3.65 \mathrm{~m}$, hence:

$$
A(l c)=3.56 \mathrm{t} / \mathrm{ml}
$$

Case of two charged channels, we have: $\mathrm{a} 1=1$, a $2=$ $0.96, \mathrm{~V}=7.3 \mathrm{~m}$, hence:

$$
A(l c)=7.12 t / m l
$$

\section{System Bc:}

The Bc convoy consists of one or at most two standard trucks per lane. In the transverse direction the number of queues is less than or equal to the number of channels. The characteristics of the Bc convoy are shown in the figure below.
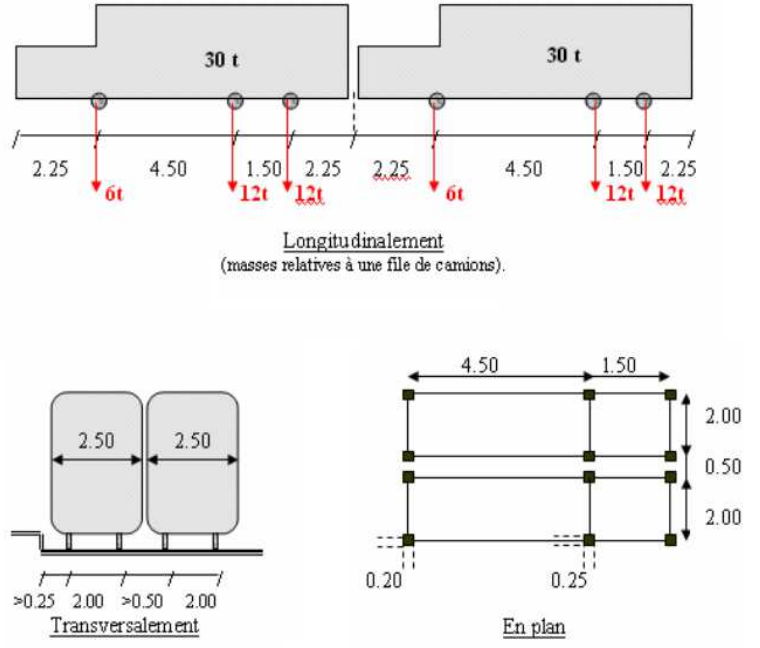

Fig. 3. The charging system Bc

System Bt :

A tandem consists of two axles with pneumatic single wheels. The characteristics of the system Bt are shown in figure 4 .

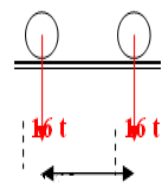

Longitudinalement (Pour un seul tandem)
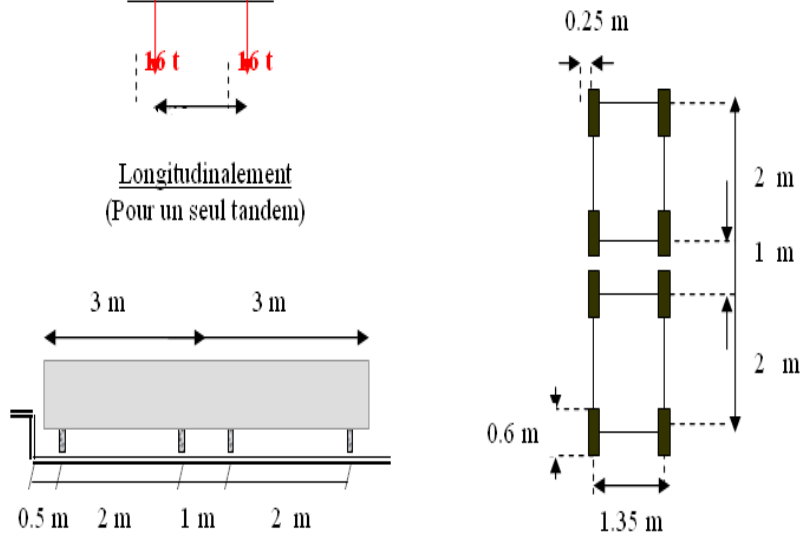

Fig. 4. System Bt

\section{Earthquakes - Dynamic Analysis of Bridges}

\subsection{Fundamentals of Dynamic Analysis}

Every structure acts statically and dynamically when subject to displacements or loads. In dynamic responses, the structures will have additional inertial forces which, according to the second law of Newton, are equal to their mass multiplied by acceleration. Thus, if the loads or displacements are enforced very slowly, the inertia forces can be ignored since the time can be assumed as zero and a static load analysis can be justified. Hence, dynamic analysis is a simple extension of static analysis.

Wilson (2002) stated that the force equilibrium of a multi-degree-of-freedom lumped mass system as a 
function of time can be expressed by the following relationship:

$F(t) I+F(t) D+F(t) s=F(t)$

in which the force vectors at time $t$ are:

$\mathrm{F}(t) I$ : is a vector of inertia forces acting on the node masses

$\mathrm{F}(t) D$ : is a vector of viscous damping, or energy dissipation, forces

$\mathrm{F}(t) S$ : is a vector of internal forces carried by the structure

$\mathrm{F}(t)$ :is a vector of externally applied loads

Equation (1) is based on physical laws and is valid for both linear and non-linear systems if equilibrium is formulated with respect to the deformed geometry of the structure.

For many structural systems, the approximation of linear structural behaviour is made to convert the physical equilibrium statement, to the following set of secondorder, linear, differential equations:

$M u ̈(t) a+C u(t) a+K u(t) a=F(t)$

in which $M$ is the mass matrix (lumped or consistent), $C$ is a viscous damping matrix (which is normally selected to approximate energy dissipation in the real structure) and $K$ is the static stiffness matrix for the system of structural elements. The time-dependent vectors $u(t) a$, $\dot{u}(t) a$ and $u \ddot{u}(t) a$ are the absolute node displacements, velocities and accelerations, respectively.

For seismic loading, the external loading $F(t)$ is equal to zero. The basic seismic motions are the three components of free-field ground displacements $u(t)$ that are known at some point below the foundation level of the structure. Therefore, equations can be written in terms of the displacements $u(t), u(t)$ velocities and accelerations $\ddot{u}(t)$ that are relative to the three components of free-field ground displacements (Wilson, 2002).

\section{Results and discussion}

\subsection{Analyses de variance (ANOVA)}

For each class of bridges, the response of the elements considered as the most vulnerable was analyzed according to the variation of the various parameters [9]. The elements whose response was followed are presented in Table 1.

\subsection{Parametric study for the perfect reinforced concrete bridge}

A full factorial defined in table 2 and consisting of $3^{3}=27$ combination was formed. a finite element model was built under ANSYS software. a finite element model convergence, for the case of the reinforced concrete bridge, the calculations were carried out in the Ansys software for the entire combination 27.

Table 1. Range of variation of the considered factors reinforced concrete bridge

\begin{tabular}{lccc}
\hline Parameter & $\begin{array}{l}\text { Height } \\
(\mathbf{m})\end{array}$ & density & Load(t) \\
& 6 & 2500 & $1,1 \mathrm{E}+02$ \\
\hline lower threshold & 7 & 3000 & $1,2 \mathrm{E}+02$ \\
\hline $\begin{array}{l}\text { intermediate } \\
\text { value }\end{array}$ & 8 & 3500 & $1,3 \mathrm{E}+02$ \\
\hline $\begin{array}{l}\text { higher } \\
\text { threshold }\end{array}$ & & & \\
\hline
\end{tabular}

Table 1 is a full factorial design of experiment table consisting of $3^{4}=81$ combinations was formed. Calculations were performed for each of these combinations under Ansys software. The most adverse case was found to be given by the parameters shown in table 2. Equation II

Table 2.The obtained stress as function of the combination number.

\begin{tabular}{|c|c|c|c|c|}
\hline $\begin{array}{l}\text { Combination } \\
\text { number }\end{array}$ & $\begin{array}{l}\text { Height } \\
\text { (m) }\end{array}$ & Load (t) & density & stress $(\mathbf{P a})$ \\
\hline 1 & 6 & $1,2 \mathrm{E}+02$ & 2500 & 427582 \\
\hline 2 & 6 & $1,2 \mathrm{E}+02$ & 3000 & 427582 \\
\hline 3 & 6 & $1,2 \mathrm{E}+02$ & 3500 & 427581 \\
\hline 4 & 6 & $1,25 \mathrm{E}+02$ & 2500 & 631229 \\
\hline 5 & 6 & $1,25 \mathrm{E}+02$ & 3000 & 631229 \\
\hline 6 & 6 & $1,25 \mathrm{E}+02$ & 3500 & 631229 \\
\hline 7 & 6 & $1,3 \mathrm{E}+02$ & 2500 & 783241 \\
\hline 8 & 6 & $1,3 \mathrm{E}+02$ & 3000 & 783241 \\
\hline 9 & 6 & $1,3 \mathrm{E}+02$ & 3500 & 783241 \\
\hline 10 & 7 & $1,2 \mathrm{E}+02$ & 2500 & 327582 \\
\hline 11 & 7 & $1,2 \mathrm{E}+02$ & 3000 & 337765 \\
\hline 12 & 7 & $1,2 \mathrm{E}+02$ & 3500 & 347544 \\
\hline 13 & 7 & $1,25 \mathrm{E}+02$ & 2500 & 531279 \\
\hline 14 & 7 & $1,25 \mathrm{E}+02$ & 3000 & 521276 \\
\hline 15 & 7 & $1,25 \mathrm{E}+02$ & 3500 & 506547 \\
\hline 16 & 7 & $1,3 \mathrm{E}+02$ & 2500 & 638761 \\
\hline 17 & 7 & $1,3 \mathrm{E}+02$ & 3000 & 603298 \\
\hline 18 & 7 & $1,3 \mathrm{E}+02$ & 3500 & 380765 \\
\hline 19 & 8 & $1,2 \mathrm{E}+02$ & 2500 & 367572 \\
\hline 20 & 8 & $1,2 \mathrm{E}+02$ & 3000 & 357598 \\
\hline 21 & 8 & $1,2 \mathrm{E}+02$ & 3500 & 427598 \\
\hline 22 & 8 & $1,25 \mathrm{E}+02$ & 2500 & 431229 \\
\hline 23 & 8 & $1,25 \mathrm{E}+02$ & 3000 & 421879 \\
\hline 24 & 8 & $1,25 \mathrm{E}+02$ & 3500 & 402971 \\
\hline 25 & 8 & $1,3 \mathrm{E}+02$ & 2500 & 483298 \\
\hline 26 & 8 & $1,3 \mathrm{E}+02$ & 3000 & 473098 \\
\hline 27 & 8 & $1,3 \mathrm{E}+02$ & 3500 & 469876 \\
\hline
\end{tabular}


Table 2 gives the obtained results as function of the Parameters. For the case of the bridge, calculations were performed under Ansys software for all of the 27 combinations. Figure 5 gives the obtained the stress as function of the combination number.

The most adverse case was found to be given by the parameters of combination 3 for which $\mathrm{H}=7 \mathrm{~m}, \mathrm{~L}=1.2$ $\mathrm{E}+02$ tand $\mathrm{d}=2500$, the lowest stress is $\sigma=327582 \mathrm{MPa}$ Then corresponding to the following configuration:

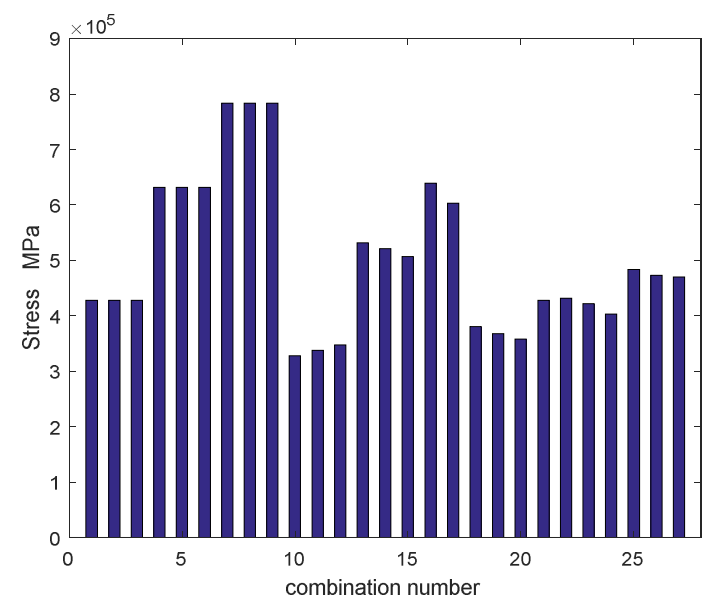

Fig. 5. Perfect shape of the bridge according to the combination (Following $\mathrm{x}$ )

These factors were varied for the last case according to Table 2This resulted for each defect configuration case and with Following $x$. In 27 combinations. Then a DOE full factorial table was considered for the bridge case. The obtained results are shown in Fig. 6, where the non dimensionalized stress defined as the stress is given as function of the combination number as resulting from the following order ( $\mathrm{H}, \mathrm{L}$ and $\mathrm{d})$.

The RSM model as obtained by quadratic polynomial regression using results of the perfect shell in terms of function of parameters $\mathrm{x}_{1}=\mathrm{H}, \mathrm{x} 2=\mathrm{L}$, and $\mathrm{x}_{3}=\mathrm{d}$ writes:

$\sigma_{c r}\left(x_{1}, x_{2}, x_{3}\right)=1.9-4.2 .10^{-10} x_{1}+2.56 .10-^{1} x_{2}-1.3 .10^{-10} x_{3}$ $-2.2 .10^{-20} x_{1} x_{2}+2.19 .10-{ }^{18} x_{1} x_{3}-2.3 .10{ }^{20} x_{2} x_{3}+3.47 .10^{-}$ ${ }^{22} x_{1}{ }^{2}+1.8 \cdot 10^{-25} x_{2}{ }^{2}+3.4 \cdot 10-{ }^{10} x_{3}{ }^{2}$

The quadratic polynomial regression de fined by Eq. (3) has an $\mathrm{R}^{2}=97 \%$ value, showing that it is good Enough to represent a RSM for the stress as Function of the considered factors within their ranges as defined in Table 1. The analysis of variance of the obtained results has shown that $\mathrm{x}_{1}=\mathrm{H}$ has the greatest influence with Fisher statistics $(\mathrm{F}=29228,3)$, it is followed by $\mathrm{x}_{2}=\mathrm{L}$ with $(\mathrm{F}=$ $540,8)$ and then comes the interaction between $\mathrm{H}$ and $\mathrm{d}, \mathrm{x}_{1} * \mathrm{x}_{3}=\mathrm{H} * \mathrm{~d}$ with $(\mathrm{F}=29228,9)$.

The associated $\mathrm{R}$-square values are $\mathrm{R}^{2}=99.9 \%, \mathrm{R}^{2}=99.6 \%$ and $\mathrm{R}^{2}=98 \%$. These indicate that the interpolations are quite good for all the base shears and that the quadratic surface response models can be used to predict theses efforts within the intervals of interpolation.
Let us assume that the design load against buckling is taken to be $\sigma$ lim. Thus, the performance function for the perfect bridge writes as:

$$
G_{l}\left(x_{1}, x_{2}, x_{3}\right)=\sigma_{l i m}-\sigma_{c r}\left(x_{1}, x_{2}, x_{3}\right)
$$

A reliability analysis was performed assuming that $\mathrm{x}_{1}, \mathrm{x}_{2}$ and $\mathrm{x}_{3}$ are random variables. Table 3 gives the means and standard deviations for these variables. Two types of probability distribution functions were considered: normal and lognormal. The design load was chosen with a standard deviation of $10 \%$.

Table 3. Means and standard deviation for Reinforced Concrete Bridge design parameters

\begin{tabular}{ccc}
\hline Random variable & Mean & Standard deviation \\
\hline$x_{1}$ & 7 & 0.7 \\
$x_{2}$ & 1250 & 125 \\
$x_{3}$ & 3000 & 300 \\
\hline
\end{tabular}

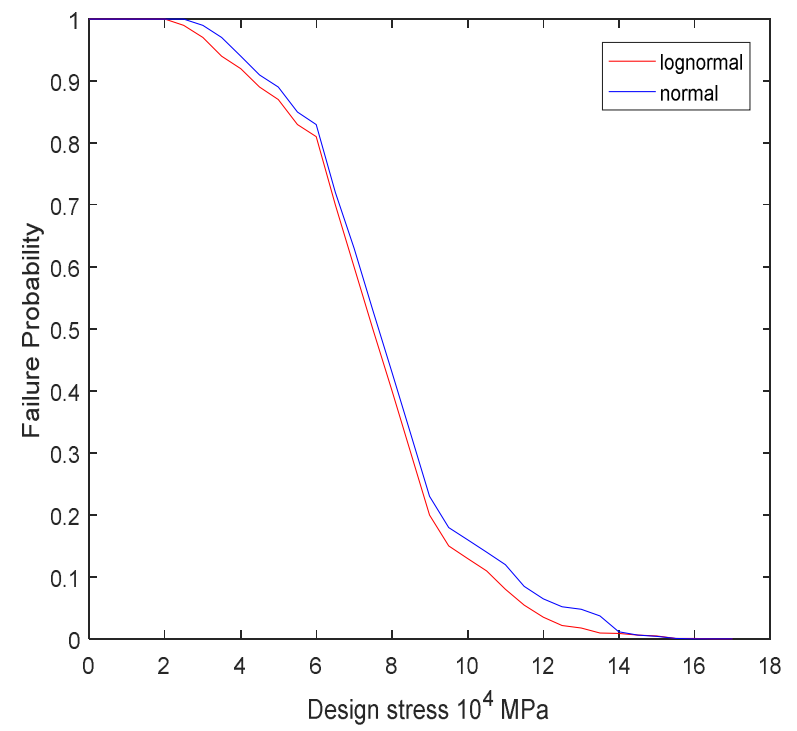

Fig.6. Reinforced Concrete Bridge, variations of failure probability as function of the design Bridge stress

Figure 6 gives the probability of failure $P_{f}$ as function of the chosen stress design in case of the perfect Reinforced Concrete Bridge.

From Figure 6, we see that the normal and lognormal distributions of the probabilities have a strong influence on the results obtained. The design stress must be lower than $15.10^{4} \mathrm{MPa}$, to avoid cracking of the bridge with great confidence.

This indicates that the identification of the probability distribution functions is very important in order to carry out an accurate analysis of the reliability, particularly in 
the useful domain of the small probabilities of failure, for example in the art of work on all the building and the bridge.

\section{Conclusions}

The vulnerability assessment of bridges is useful for seismic retrofitting decisions, disaster response planning, estimation of direct monetary loss, and evaluation of loss of functionality of highway transportation systems. This paper illustrates the results the analysis of the reliability of the bridges against the siege, as this phenomenon could be affected by catastrophic consequences on the structure. Models of these design performance states were obtained by modeling the response surface and quadratic polynomial regression. Then, the reliability analysis of the form was conducted. The results obtained have shown that the distribution of probabilities has a significant influence on the reliability of the $\mathrm{x}$-axis counterpart and in the useful domain of the small probabilities of failure. The dependencies on the chosen distribution of probabilities are not the same for all the situations analyzed.

\section{References}

[1] Kircher CA, Wihtman RV,Holmes WT.Hazus earthquake loss estimation methods Nat Hazards Rev 2006;7(2):45-59.

[2] Hazuz-MH.Multi-hazard loss estimation methodology:earthquake model. Washington (DC):Departement of Homeland security,FEMA;2003.

[3] Mackie K, Stojadinovic B.Probabilistic seismic demand model for California highway bridge.J Bridge Eng 2001,6(6):468-81.4

[4] Mackies KR,Stojadimovic B.fragility basis for California highway over pass bridge seismic decision making PEER report 2005/12.Berkeley (CA):Pacific Earthquake Engineering Research center ,University of California:2005.

[5] Powell, G. H., and Allahabadi, R (1988). "Seismic damage predictions by deterministic methods: concepts and procedures."Earthquake Eng. Struct. Dyn, 16. pp. 719-734.

[6] Giberson M (1969). "Two nonlinear beams with definitions of ductility", Journal of Structural Division, ASCE, vol. 95, $\mathrm{n}^{\circ}$ 2. pp. 137-157.

[7] Kondner RL. Hyperbolic stress-stain response: cohesive soils. J Soil Mech Found Div, ASCE 1963;89(1):115-43.

[8] Duncan JM, Chang CY. Nonlinear analysis of stress and strain in soils. ASCE J Soil Mech Found Div 1970;96(M 5):1629-53.

[9] Cardonne, D., Perrone, G. et M., D. (2007). Seismic risk assessment of highway 